\title{
8 | AIDS, science and citizenship after apartheid
}

\author{
STEVEN ROBINS
}

\section{Introduction: science, race and cultures of colonialism}

AIDS statistics in South Africa have unleashed an extraordinary amount of political heat, controversy and contestation, with the government persistently questioning the reliability of these statistics and projections. Matters came to a head in 2001 with the 'leak' to the press of a Medical Research Council (MRC) report that estimated that 'AIDS accounted for about $25 \%$ of all deaths in the year 2000 and has become the single biggest cause of death' (Dorrington et al. 2001: 6). The government's initial response to the MRC report was to challenge its findings by claiming that 'violent death', not AIDS, was the single biggest cause of death. This triggered a major controversy which raged in the media, culminating in the government's concerted efforts to 'delay' the release of the MRC report. In addition, government applied considerable pressure to the chairperson of the board of the MRC to institute a 'forensic enquiry' to uncover the source of the press 'leak'. The president of the MRC, Dr William Makgoba, was also subjected to relentless pressure to withdraw the report, with government spokespersons claiming that its findings were 'alarmist' and 'inaccurate'.

One of the possible interpretations of this response from government was that the findings were perceived to imply that the government was not managing the pandemic effectively and that the situation was 'out of control', which could have negative impacts in terms of much-needed overseas investment. Other possible reasons include discomfort with the findings among certain sectors of government and the ruling ANC party, who believed that the report reinforced media and popular beliefs and prejudices that AIDS is a 'black disease' concentrated in the rural areas of the former black 'homelands' of KwaZulu-Natal and Eastern Cape provinces. This racial and geographical 'profiling' of AIDS, it would appear, shaped both state and citizen responses. The questions of race and identity, I argue, lie at the heart of responses to the AIDS pandemic and to AIDS science. The racialized character of these responses was not, however, confined to President Mbeki's inner circle. It has been more widespread.

In December 2002, the Human Science Research Council (HSRC) released a study that questioned popular perceptions about the racial and 
geographical distribution of AIDS. A large-scale household survey was conducted to determine the HIV prevalence rates in different provinces among races, sexes and geographical locations. In an article entitled 'AIDS survey shatters stereotypes', the Mail and Guardian (6 December 2002) reported that 'KwaZulu-Natal has shaken off the tag of having the highest HIV-prevalence rate [and] the Western Cape gets a wake-up call because its HIV prevalence rate of $10.7 \%$ is higher than the $8.6 \%$ revealed by [the MRC] antenatal survey'. ${ }^{1}$ The article also noted: 'a surprising finding is that the Eastern Cape has the lowest prevalence rate $(6.6 \%)^{\prime} .{ }^{2}$ In contrast to studies that indicated that AIDS prevalence was highest among poor, rural, uneducated black people of the former homelands, the HSRC study found that highly mobile urban people in the informal settlements and townships, as well as the middle classes, were most certainly at risk.

Notwithstanding this challenge to AIDS stereotypes and prejudices, the 'cold facts' of AIDS statistics are likely to continue to produce competing interpretations, including those that construct AIDS as a 'black disease'. It is therefore quite conceivable that African nationalists such as President Mbeki interpreted these statistics as evidence of a long colonial and apartheid legacy of scientific racism. In other words, they were read through the colour-coded lens of colonial histories of discrimination and dispossession. For Mbeki and his 'dissident' supporters, such findings were not the product of neutral, rational and universal scientific inquiry, but were understood as the products of historically constructed and politically driven processes embedded in specific histories of colonialism, apartheid and capitalism.

In South Africa, the dissident debate and the numerous cultural obstacles encountered when implementing AIDS prevention programmes have forced scientists, non-governmental organizations (NGOs), AIDS activists and government to acknowledge and respond to 'local' and 'lay' interpretations of AIDS. These include the blaming of AIDS on witchcraft, as well as a variety of AIDS conspiracies: 'whites' who want to contain black population growth; 'white doctors' who inject patients with AIDS when they go for tests; the CIA and pharmaceutical companies who want to create markets for drugs in Africa; the use of Africans as guinea pigs for scientific experiments with AIDS drugs; beliefs that sex with virgins, including infants, can cure AIDS; and beliefs that anti-retrovirals (ARVs) are dangerously toxic. But perhaps the most daunting problem for AIDS activists and health professionals was the President's initial flirtation with AIDS 'dissident' theories and the implications this had in terms of attempts to establish AIDS treatment programmes. The President's position, along with a plethora of popularly held 'AIDS myths' and the stigma and shame associated with AIDS, contributed to defensive responses and AIDS denial 
among the general population as well as within the President's inner circle of policy-makers and politicians. What are the implications of all this for contemporary debates on science and citizenship in a globalizing world?

The AIDS pandemic in South Africa raises a number of troubling dilemmas for attempts to democratize science. Given the relative weakness of African states and the extremely thin spread of scientific knowledge and institutions, what can citizen science, popular epidemiology, ethnoscience and indigenous knowledge do to deal with a lethal pandemic such as AIDS? Or would state legitimation of these public knowledges not further undermine already weak scientific institutions and biomedical knowledge regimes? What does citizen science mean in contexts where contestation between the public's and experts' forms of knowledge and science threatens to undermine biomedical scientific authority and AIDS interventions that could potentially save lives? What about contexts where contestation over AIDS science becomes highly politicized because governments are distrustful of the autonomy of the scientific establishment, or where 'indigenous knowledge' and 'local solutions' are reified as part of cultural nationalist ideologies and programmes? What about situations where people's own knowledge and practices result in AIDS denial, violence and oppression; for instance, when the South African AIDS counsellor Gugu Dlamini revealed her HIV-positive status to rural villagers, who responded by killing her for bringing shame and disease to her community?

This chapter explores what notions such as the 'democratization of science' could look like from the epicentre of the worst public health hazard in Africa's history. It focuses on the opportunities and constraints that exist for mediation and negotiation between various experts and publics given this state of emergency. The AIDS pandemic raises particularly difficult questions concerning the role of deliberative and inclusionary processes in scientific domains: Who is to be invited into what forums? What do these deliberative processes mean in contexts where scientific authority is distrusted both by powerful individuals within the state, and by large sections of the public?

By focusing on the responses and strategies of government, AIDS activists and civil society organizations such as Treatment Action Campaign (TAC), it is possible to begin to address some of these questions. A case study investigates TAC's strategies of engagement with scientists, the media, the legal system, NGOs and government, as well as its grass-roots mobilization, AIDS treatment literacy campaigns and AIDS awareness campaigns. It examines the opportunities and limits that framed TAC's interactions within these different spaces.

This investigation of the relations between citizens, scientists and 